\title{
Sorting of Spent Electric Vehicle Batteries for Second Life Application
}

\author{
M. Muhammad, P. S. Attidekou, M. Ahmeid, Z. Milojevic, S. Lambert \\ School of Engineering, Newcastle University \\ Newcastle upon Tyne, United Kingdom \\ e-mail: musbahu.muhammad@ncl.ac.uk, simon.lambert@ncl.ac.uk
}

\begin{abstract}
Electric vehicles (EV) typically have around $80 \%$ of their initial capacity at the end of the battery life. It is widely anticipated that these EV batteries will retain significant capacity remaining and potentially operate for additional years in their second life. Finding ways to repurpose the batteries in home, industrial and grid-scale energy storage system (ESS) is becoming more urgent. Establishing or verifying battery performance in comparison to these targets is a principal objective. Non-availability of onboard diagnostics data and accurate assessments of the automotive and second use battery degradation stand out in particular. This paper characterises the energy and power density of a cell using a hybrid pulse power characterisation (HPPC) test. Experimental results from five randomly selected cells from disassemble Nissan leaf pack that reach end of life (EoL) shows that all the cells satisfied the ESS performance targets of electric vehicle (EV) of $700 \mathrm{~W} / \mathrm{Kg}, 300 \mathrm{~W} / \mathrm{Kg}$ during discharge/regen respectively. The paper further proposes the used of HPPC micro cycle based on offline data for feature extraction to distinguish between power and energy density of the cell in $80 \mathrm{~s}$, which is significantly quicker.
\end{abstract}

Keywords-sorting; EoL Lithium-ion batteries; hybrid pulse power characterization; repurposing

\section{INTRODUCTION}

Battery reuse strategies in which a battery pack first serves an automotive application, then once deemed appropriate is redeployed into a secondary market could help overcome lithium-ion battery cost barriers to the deployment of both electric vehicles (EVs) and grid-connected energy storage.

By extracting additional services and revenue from the battery in a post-automotive application, can increase their lifespan and usefulness, with benefits ranging from potential cost savings for consumers to environmental gains. Such battery reuse strategies would not only reduce the dependence on fossil fuel and emissions of greenhouse gases by increasing EV adoption, but would also improve the reliability, efficiency, and cleanliness of the grid by advancing the deployment of grid-connected storage. Recognizing this potential, it is worth investigating the feasibility of and major barriers to the second use of modern lithium-ion EV batteries.

Many researchers revealed that the reuse of EV batteries is viable and valuable [1]-[4]. In addition, repurposing EV batteries could become indispensable for both the automotive and electricity industries. There are numerous emerging grid- related applications where the reuse of EV batteries would be beneficial to consumers and utilities. For example, renewable energy integration, regulation energy management, demand charge management, peak demand reduction, and transmission upgrade deferral.

However, the economic margins that make reuse viable are often small, and thus several factors could affect this conclusion. The major impediment being the complexities of repurposing heterogeneous batteries, collection and technical labour are the primary cost element. Furthermore, nonavailability of onboard diagnostics data and accurate assessments of automotive and second use battery degradation stand out in particular. Use of vehicle diagnostics data to confirm the state of health $\mathrm{SoH}$ and absence of faulty cells in modules/battery packs prior to their purchase is, therefore, key to repurposing.

It becomes necessary to study the baseline health of all EV batteries and developed a testing protocol to assess and sort battery at the End of their automotive life prior to second-use. This will enable accurate identification of a battery's value and its viability for second use service. Reused batteries should be able to demonstrate that a product of adequate reliability can be provided at low cost.

Whilst, the most promising application for second-life $\mathrm{EV}$ batteries is the energy storage system (ESS). The main primary requirement of the said application is energy and power density. In order to meet the energy requirement of the ESS, the system is usually built using energy storage devices (ESD) with higher power and energy density. However, such ESS can also be built using second-life batteries that satisfy the end of life EoL characteristics of energy storage system performance targets for EVs [5].

In general, lithium ion batteries testing is divided into three broad phases i.e., characterisation, life test and reference performance test (RPT). Characterisation test establishes the capability/baseline performance. Life testing comprises of both cycle and calendar life and establishes behaviour over time at various temperature, state of charge SoC plus other stress conditions; whilst RPT track the evolution of performance over cell life and are performed periodically during the battery life testing as well as the beginning of life (BoL) and EoL [5]-[7].

Typical parameters for defining the electrical performance of Li-ion cells are capacity, resistance, opencircuit voltage (OCV) and hybrid pulse power characterisation (HPPC), etc. Essentially, the capacity measures the amount of electric charge stored in a cell and 
defines its maximum capacity in the application under a given load. On one hand, the resistance characterises the cell dynamics whilst the OCV test gives information about the thermodynamic properties of the cell under test. On the other hand, HPPC provides the battery dynamic power capability in both discharge and regen regimes. The energy and power capabilities are then used to derive the peak power and available energy.

The primary aim of this work is to demonstrate the assessment and sorting of the EoL EV batteries with unknown history to meet the requirements of repurposing in ESS. This demonstration is accomplished via the HPPC technique [5].

\section{BATTERY PACK DESIGN}

The Nissan Leaf is one of the most recognisable EV on the road and its first-generation battery pack has a capacity of $24 \mathrm{KWh}$. The pack consists of 48 modules arranged into three distinct sections, a stack in the rear and a stack on the left-hand and right-hand side of the pack. Each module comprises of four individual pouch cells. The cells are electrically configured as $2 \times 2$ arrangement ( 2 in series and 2 in parallel). The cell chemistry is lithium-manganese-oxide with nickel oxide widely known as (LMO)

\section{A. Characterisation}

After the battery pack disassembly to the module level, basic characteristics including capacity, AC impedance and HPPC were conducted. The capacity was measured using constant current- constant voltage (CC-CV) method followed by the default rest of $1 \mathrm{hr}$ at $C_{1}$ rate for three consecutive discharge capacities. Electrochemical impedance spectroscopy (EIS) is used for AC impedance measurement. Prior to the EIS test, the battery is rested for a period of $1 \mathrm{hr}$ to ensure equilibrium followed by $5 \mathrm{mV}$ sine signal sweep from $V_{\min } 3 \mathrm{Khz}-10 \mathrm{mHz}$ in potentiostatic mode [8], [9].

\section{B. $H P P C$}

Characterising the performance of batteries under different operating conditions, such as those found in EV applications has been identified as a key factor in the development of automotive batteries. One metric, which provides very useful results, HPPC, has been the subject of much interest in recent years. A standard test procedure exists for determining HPPC performance in automotive batteries [5] and detailed investigations have been performed into the requirement of HPPC and its performance on plug-In hybrid electric vehicle (PHEV) [6], EVs [5]. A full discussion of the HPPC test procedure is beyond the scope of this paper, for detailed information see [5]-[7]; a brief outline of the salient points is given here for clarity, however.

Fundamentally, is a measure of battery's dynamic power capability over its useable voltage ranges incorporating a discharge and regeneration current pulses. The HPPC procedure determines this ability by applying current waveforms as shown in Fig. 1 to the battery under test, the response to this stimulus is used to determine power capability. The test comprises of 30 s discharge, 40 s rest and immediately followed by 10 s regen; together these make up one complete HPPC micro cycle. Between each pair of the micro cycle, the battery is discharged to the next $10 \%$ depth of discharge (DoD) level based on the operating capacity. It is worth noting that the current values in Fig. 1 are relative

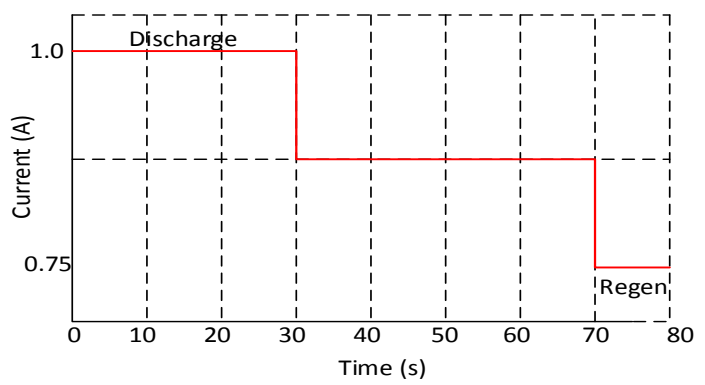

Figure 1. HPPC Tet microcycle.

and the HPPC micro cycle is not charge balance i.e.

$$
\int_{0}^{30} I(t) d t \neq \int_{70}^{80} I(t) d t
$$

The pulsing allows Ohmic resistance of the battery to be calculated and permits the dynamic energy of the battery to be related to the power capability as a function of DoD. The technique further allows the Battery Size Factor (BSF) to be calculated. The BSF indicates how many devices under test would satisfy specific energy combinations of ESS and power delivery target. Furthermore, in addition to the HPPC procedure, the test manuals describe the energy storage performance target for different $\mathrm{EV}$ relative to system size.

\section{TEST PROCEDURE}

The test procedure described above is applied to five cells: A, B, C, D \& E, all of which are randomly selected from the disassemble 2011 Nissan Leaf battery pack that reach EoL in an automotive application. The complete test sequence, commences by charging the battery with $\mathrm{C} / 3$ (22A) to $V_{\text {max }}$ of $4.2 \mathrm{~V}$ using $\mathrm{CC}-\mathrm{CV}$ procedure. Following a rest of $1 \mathrm{hr}$, a HPPC micro cycle is executed and subsequent discharge to the next $10 \%$ depth of discharge using $\mathrm{C} / 3$. This procedure is repeated until the $V_{\min }$ of $2.7 \mathrm{~V}$ is reached. To achieve a more conservative estimate of pulse resistance a low current of $1 \mathrm{C}$ rate of $66 \mathrm{~A}$ is used during the HPPC profile.

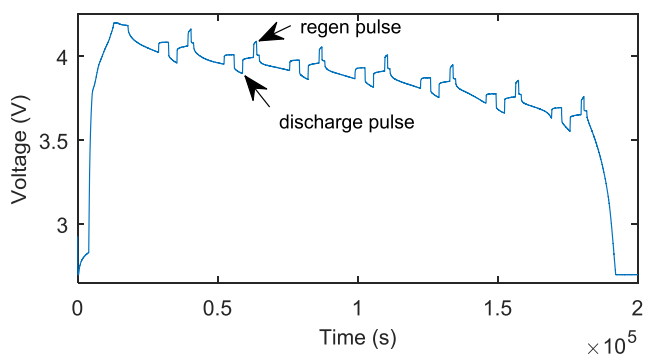

Figure 2. Voltage vs time during the HPPC cycle.

Fig. 2 illustrate the voltage vs time for the battery. The discharge pulses are clear whilst the $10 \mathrm{~s}$ regen pulse appeared as a spike in the waveform. after which there are 
several minutes of discharge at $1 \mathrm{C}$ rate which decreases the battery capacity by $10 \%$. This is followed by one-hour default rest prior to the application of the subsequent HPPC micro cycle. The pulse resistance is calculated for each HPPC micro cycle by dividing the change in voltage during the 30 s discharge and 10 s regen periods by the applied current.

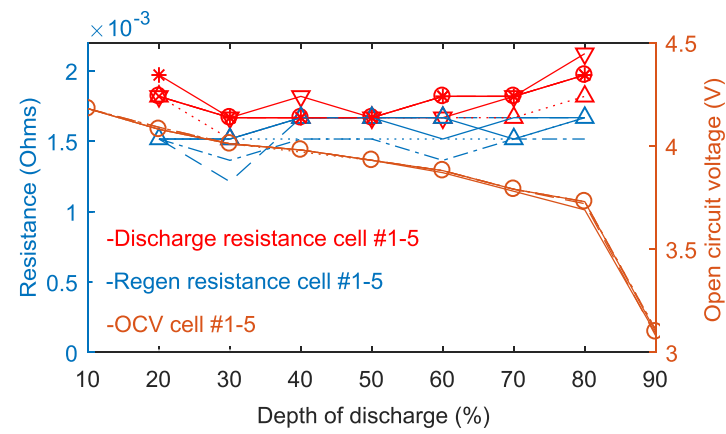

Figure 3. Discharge, regen resistance and OCV vs DOD.

Fig. 3 shows the plot of the discharge and regen resistance calculated using (2) at each $10 \%$ increment of the DOD. The calculated percentage is based on the cumulative capacity removed divided by the rated capacity. As can be seen, the 10 s regen resistances are slightly shifted to the right compared to the $30 \mathrm{~s}$ discharge resistances due to the inclusion of the charge removed from the discharge pulse when determining the percentage of the rated capacity removed for the regeneration regime. Furthermore, there are minor differences between the discharge and regen resistances. As the cell discharges the resistance increases. In addition, the OCV is also plotted in the same figure. OCV between each $10 \%$ increment can be estimated by straightline interpolation. From these resistance values, the maximum pulse power capability can be determined using equation (3) and (4).

$$
\begin{gathered}
R_{\text {discharge } / \text { regen }}=\frac{\Delta V}{I_{\text {discharge } / \text { regen }}} \\
P_{\text {discharge }}=\frac{V_{\min }\left(O C V_{\text {discharge }}-V_{\text {min }}\right)}{R_{\text {discharge }}} \\
P_{\text {regen }}=\frac{V_{\text {max }}\left(V_{\text {max }}-O C V_{\text {regen }}\right)}{R_{\text {regen }}}
\end{gathered}
$$

where $O C V_{\text {discharge }}$ and $O C V_{\text {regen }}$ are the $\mathrm{OCV}$ of the battery immediately prior to applying either the discharge or regen pulse. $V_{\min }, V_{\max }$ are the minimum and maximum terminal voltages limits within which the battery is cycled.

Fig. 4 shows the discharge and regen pulse power capability of the five cells as function of DoD of the cells. There is a clear distinction between the discharge and regen power capability despite the similarity in values of discharge and regen pulse resistances. This is due to overpotential as a result of driving high current during cycling. As can be seen from the figure all the five cells have satisfied the requirement of the ESS storage system performance targets for EVs of $700 \mathrm{~W} / \mathrm{Kg}$ and $300 \mathrm{~W} / \mathrm{Kg}$ for discharge and regeneration power capability respectively as shown in Table 1 ; in all the working region from $80 \%$ to $20 \%$ DOD.

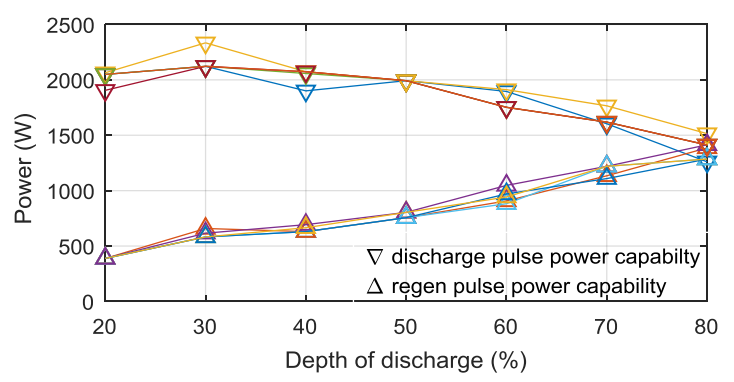

Figure 4. Pulse power capability vs DOD.

TABLE I. ENERgy Storage Sytem Performance TARget For EV

\begin{tabular}{|l|l|c|c|}
\hline Energy C/3 Rate & Units & System level & Cell level \\
\hline $\begin{array}{l}\text { 30s Peak discharge } \\
\text { power }\end{array}$ & $\mathrm{W} / \mathrm{Kg}$ & 470 & 700 \\
\hline $\begin{array}{l}\text { 10s Peak regen } \\
\text { power }\end{array}$ & $\mathrm{W} / \mathrm{Kg}$ & 200 & 300 \\
\hline
\end{tabular}

Fig. 5 shows the discharge and regen pulse power capability of the cells as a function of the cumulative energy removed from the cells. This is achieved with the assumption that the measured capacity removed from the constant power discharge and subsequent HPPC test are equivalent. The pulse power capability of cell $\mathrm{A}$ and $\mathrm{B}$ is distinct in all the region having disparity of $159 \mathrm{Wh}$ and $254 \mathrm{Wh}$ respectively. The three remaining cell exhibits similar discharge pulse power capability in all regions. The distinction in regen pulse power capability is also apparent between cell $\mathrm{A}$ and $\mathrm{B}$ with a magnitude of $27 \mathrm{Wh}$ at $80 \%$ DoD.

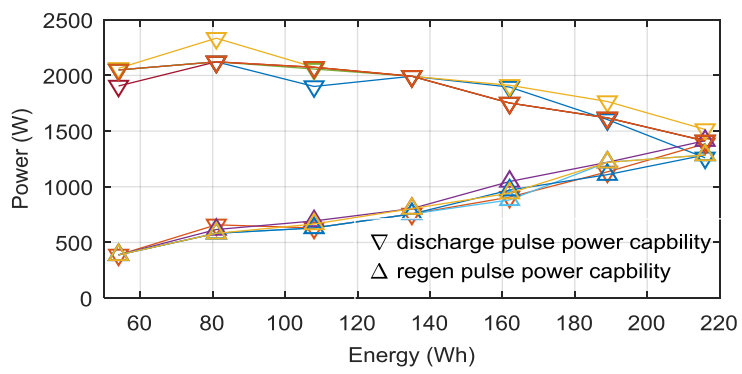

Figure 5. Pulse power capability vs energy removed.

Having obtained the pulse power capabilities, the total cell useable energy as a function of power level the device is being operated can be determined. The useable energy is the amount of energy that a cell can accept or deliver when it is being cycled at a certain power level. The battery size factor (BSF) of a target application can then be determined using the useable energy as a function of power.

\section{BATTERY SORTING}

Batteries can be sorted into different types, chemistry and SoH optically or electrically. Optical sorting is based on the 
physical appearance of the battery, whilst electrical technique involves measuring the electrical parameters of the battery. This work focuses on the sorting of the battery by means of electrical measurement via HPPC.

\section{A. Modelling the HPPC Micro Cycle}

Here, the modelling takes the approach of representing the various loses inside the battery such as Ohmic resistance $R_{O}$, charge transfer resistance $R_{C T}$ and the diffusion resistance $R_{\text {dif }}$. Fig. 6 shows a cell voltage response due to current perturbation. As previously mentioned the aim of this work is to predict the automotive EoL for any given HPPC micro cycle based on discharge/regen pulse power capability. To do this it is necessary to predict the way the impedance changes with charge depletion and charge sustenance in a micro cycle. The impedance parameters are essentially describing the electrochemical reaction and mass transport inside the battery, they are affected by the battery internaltemperature, the load current and the ionic concentration of reactants. During discharge/regen, the current flow and heat generated by the reaction causes a rise in temperature, increases the ion mobility within the electrolyte and consequently increase in the self-discharge and Ohmic resistance $R_{O}$. End of discharge/regen is reached at the end of $30 \mathrm{~s} / 10 \mathrm{~s}$ discharge/regen period or when the cell voltage reaches the minimum or maximum voltage threshold $V_{\min }, V_{\max }$ respectively. The voltage at the end of both discharge/regen for a cell current $I$ is given by

$$
\begin{aligned}
& V_{D}=V_{D O C V}-I_{D}\left(R_{O r}+R_{C T d}+R_{d i f_{-} d}\right) \\
& V_{R}=V_{R O C V}+I_{R}\left(R_{O r}+R_{C T r}+R_{d i f_{-} r}\right)
\end{aligned}
$$

where $V_{D}, V_{R}$ are the voltages at the end of discharge/regen pulses, $V_{D O C V}, V_{R O C V}$ is the OCV of the cell prior to discharge/regen pulses respectively. For the empirical charge depletion/sustaining model considered here, the voltage is expressed in terms of the effect of changes in the internal parameters of the cell neglecting self-discharge.

$$
V_{H P P C}(t)=V_{D O C V}-\Delta V_{R T D}+\Delta V_{R}
$$

where $\Delta V_{R T D}$, is the voltage drop due to internal resitance during discharge phase.

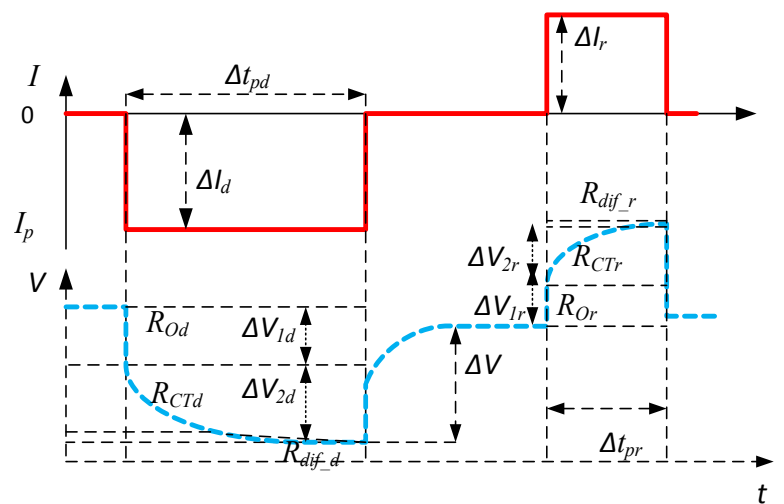

Figure 6. Cell voltage response perturbed by a HPPC micro cycle.

\section{B. End of Life Sorting}

In order to effectively determine the EoL via HPPC micro cycle, it is necessary to understand how the complete cycles work i.e. discharge/regen and rest at the end of each micro cycle. In essence, the combined effect of the HPPC micro cycle can be captured by the Coulombic efficiency $\eta_{C}$ (define as the fraction of the charge extracted from the battery to the total charge put into the battery in a complete HPPC cycle). The other factor that is also accounted for is the self-recharge during the HPPC micro cycle. This behaviour emanated due to reaction products that build up around the electrode and slow down the reaction. The rest period allows the reaction product to dissipate thus increasing the available capacity during the next cycle. For this empirical model, the self-recharge is represented with exponential as illustrated by the data. The equation for battery micro cycle aging can be written as

$$
C_{K+1}=C_{K} \eta_{C} \cdot\left(C_{1} e^{\left(-\frac{C_{2}}{\Delta t_{d}}\right)}-\Gamma_{1} e^{\left(-\frac{\Gamma_{2}}{\Delta t_{r}}\right)}\right)
$$

where $C_{K}$ denotes the charge capacity of the $K t h$ micro cycle $\Delta t_{f d}, \Delta t_{f d}$ are the relaxation periods after discharge/regen in $K$, and $K+1$ cycles. $C_{1}, C_{2}$ and $\Gamma_{1}, \Gamma_{2}$ are the discharge/regen phase constant to be determined based on the model parameters. Fig. 6 shows the validity of the equation in modelling the discharge/regen and self-recharge process for an actual Li-ion battery HPPC cycle. Although the model is used to estimate the cell voltage during the selfrecharge process. However, it was assumed that the SoC of the battery is correlated with the voltage during rest and relaxation periods in the absence of the load current to maintain the exponential function form.

\section{HPPC Micro CyCle EOL TARGETTED TEST}

In order to validate that measured HPPC micro cycle test response of a cell at EoL differs from ones at other $\mathrm{SoH}$ for example middle of life (MoL), it is necessary to benchmark the battery at EoL to ensure that any significant deviation can be distinguished. An off-line library data built from a significant number of EoL HPPC micro cycle sample data is required for comparison with the battery under test. However, an identical environmental testing condition should be provided during both tests. It is almost difficult or impossible to guarantee exact SoC, at the point of the HPPC micro cycle. However, a comprehensive library can be built at a representative $\mathrm{SoC}$ range. In essence, assigning various boundary conditions of the SoC range from $90 \%-10 \%$ capacity removal within the limits of $V_{\max }$ and $V_{\min }$

The procedure involves offline data gathering by extracting features from the sensor data which comprises of discharge/regen current, OCV, temperature reading and charge depletion/sustaining voltage. These sensor data are then used to compute the parameters of the battery, discharge/regen resistances and discharge/regen power capabilities of the battery as described in section III. Fig. 7 shows an example HPPC micro cycle voltage response of 3 cells C, D and E at 90\% capacity. As can be seen from the figure there is an excellent correlation between the cell's 
voltage during discharge, rest and regeneration regions. Such feature exhibits that of cells with similar characteristics and all the parameters (e.g. discharge/regen pulse resistances, pulse power capabilities, power and energy densities should be the same. Fig. 8 illustrate the HPPC micro cycle of all the five cells in the same $90 \%$ capacity circa. It is apparent that cell $\mathrm{A}$ and $\mathrm{B}$ have slightly different characteristic between each other and cell, C, D, E. Even though all the cells have reached EoL. Such variations in OCV, resistance, capacity and power capability is anticipated due to cell-to-cell differences arising from manufacturing variability or temperature distribution as the cell degrades despite subjected to automobile application. In other words the response of the battery $\mathrm{B}$ appears to be sluggish during the micro cycle in comparison to the batteries A, C, D, and E. This indicate that battery $\mathrm{B}$ is weakest among the five batteries. To further validate the result the capacity of all the batteries were measured, battery $\mathrm{C}$ and $\mathrm{D}$ appear to have 54 Ah capacity whilst that of battery $\mathrm{E}$ is $53.8 \mathrm{Ah}$. The two remaining cells A, B has capacity of 54.5 Ah and 50.1 Ah respectively. Furthermore, the extent of degradation would be appreciated if there exists a RPT data at the BoL that would be compared with the current EoL data.

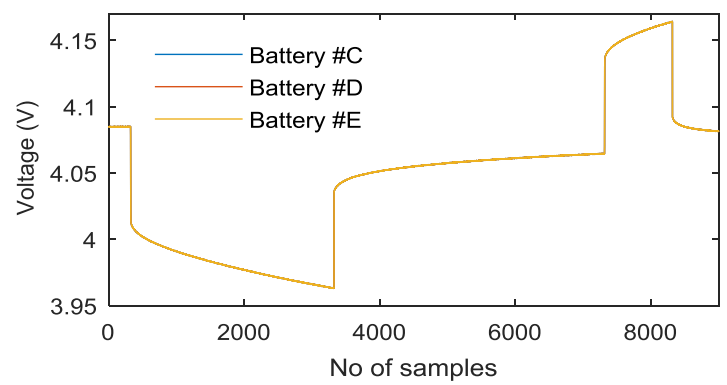

Figure 7. Example of HPPC micro cycle at $90 \%$ from 3 batteries.

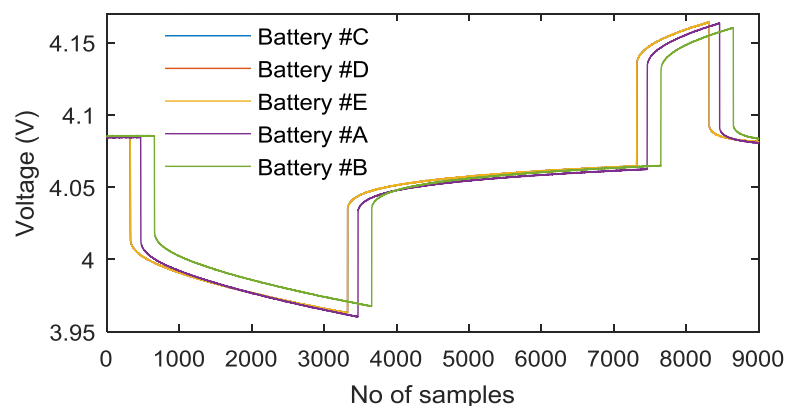

Figure 8. Vaiation of HPPC micro cycle.

\section{CONCLUSION}

Existing methods of quantifying the $\mathrm{SoH}$ of the spent automotive lithium-ion battery prior to reuse include a capacity test in which the battery is cycled. After the charge/discharge cycle the capacity is compared to the one at the BoL to determine the capacity fade. However, this technique requires time to execute and did not account for the power/energy fade of the battery which is key to ESS. This paper proposed a HPPC technique to address sorting of lithium-ion batteries and a decision matrix for repurposing. The proposed method uses the offline library of HPPC micro cycle data which is used to benchmarks the cell's response over an SoC ranges which significantly improve the test time. The discharge/regen pulses measures the mobility of ion flow and evaluate the response time during both charge and discharge, strong battery recover quickly whilst weak one appear soft and sluggish. The experimental results realised through discharge/regen pulsing validated the suitability of the technique for sorting of spent lithium-ion batteries based on strong and weaker battery with further link to power/ energy density and capacity. Importantly, the proposed technique was shown to discriminate between strong and weak batteries in $80 \mathrm{~s}$. The Future work will focus on how the HPPC micro cycle can be used as rapid test for discriminating between batteries considering only discharge or regen regimes.

\section{ACKNOWLEDGMENT}

The authors acknowledge the financial support of the Faraday Institution: ISCF Faraday Challenge Fast Start Project on "Recycling and Re-use of lithium ion batteries" made available through "EP/FIRG005".

\section{REFERENCES}

[1] G. Eason, B. Noble, and I. N. Sneddon, "Battery second life: Hype, hope or reality? A critical review of the state of the art," J. Ren.\& Sustain. Energy Rev., vol. 93, pp. 701-718, Oct 2018.

[2] Pinsky N, Gaillac L, Mendoza A, Argueta J, Knipe T. Performance of advanced electric vehicle batteries in stationary applications. In: Proceedings of the 24thannual international telecommunications energy conference; 2002. p. 366-72

[3] Pinsky N. Electric Vehicle Battery 2nd Use Study. Tech. rep., Argonne National Laboratory, Electrochemical Technology Program; 1998.

[4] Cready E, Lippert J, Pihl J, Weinstock I, Symons P, Jungst RG. Technical and economic Feasibility of applying used EV batteries in stationary applications. Tech. rep.,andia National Laboratory; 2003.

[5] J. P. Christopsen, "Battery Test Manual for Electric Vehicles," INL/DE AC07-05ID14517 Rev. 3, pp. 1-50, June 2015

[6] Battery Test Manual for Plug-In Hybrid Electric Vehicles, rev. 3, INL/DE-AC07-05ID14517 pp. 1-83, Sep 2014.

[7] FreedomCAR 42V Battery Test Manual for Power Assist Hybrid Electric Vehicles, INL/DoE/ID-11069, pp. 1-130, Oct. 2003.

[8] S. Lambert, M. Armstrong P.S. Attidekou, P.A. Christensen,, J. D. Widmer, C. Wang, and K. Scott, "Rapid Nondestructive-Testing Technique for In-Line Quality Control of Li-Ion Batteries," IEEE Trans. Ind. .Electron, vol. 64, pp. 4017-4026, May 2017.

[9] P. S. Attidekou, S. Lambert, M. Armstrong, J. Widmer, K. Scott, and P.A. Christensen, "A study of $40 \mathrm{Ah}$ lithium ion batteries at zero percent state of charge as a function of temperature," J. Power Source, vol. 269, pp. 694-703, Dec 2014. 